University of Louisville

ThinkIR: The University of Louisville's Institutional Repository

\title{
Electrocatalyst decorated hematite nanowire arrays for photoelectrochemical water splitting.
}

\author{
Erica James \\ University of Louisville
}

Follow this and additional works at: https://ir.library.louisville.edu/honors

Part of the Chemical Engineering Commons

\section{Recommended Citation}

James, Erica, "Electrocatalyst decorated hematite nanowire arrays for photoelectrochemical water splitting." (2015). College of Arts \& Sciences Senior Honors Theses. Paper 66.

http://doi.org/10.18297/honors/66

This Senior Honors Thesis is brought to you for free and open access by the College of Arts \& Sciences at ThinkIR: The University of Louisville's Institutional Repository. It has been accepted for inclusion in College of Arts \& Sciences Senior Honors Theses by an authorized administrator of ThinkIR: The University of Louisville's Institutional Repository. This title appears here courtesy of the author, who has retained all other copyrights. For more information, please contact thinkir@louisville.edu. 
Electrocatalyst Decorated Hematite Nanowire

Arrays for Photoelectrochemical Water Splitting

By

Erica James

Submitted in partial fulfillment of the requirements for Graduation summa cum laude

University of Louisville

May, 2015 


\begin{abstract}
$\underline{\text { Abstract }}$
Solar power is a leading option for renewable energy. However, storing solar energy is one of the leading pitfalls in this field, and one viable option is to store solar energy in chemical bonds, for example in $\mathrm{H}_{2}$ via water splitting. Hematite, $\alpha-\mathrm{Fe}_{2} \mathrm{O}_{3}$, is one of the possible semiconductors that has been researched to drive photoelectrolysis of water. Hematite alone is not a decent material for photoelectrolysis because of the large activation energy required to begin the reaction. To make hematite more useful for photoelectrolysis an electrocatalyst, such as nickel oxide, is needed. In this experiment, nickel (II) nitrate was dissolved into distilled water; then, the solution was applied to hematite nanowires and exposed to atmospheric oxygen plasma. This left a coating of nickel oxide particles on the surface of the nanowires. The hematite with a nickel oxide catalyst can be used in this form to drive the water splitting reaction. After plasma deposition, it can also be placed in an oven at $550{ }^{\circ} \mathrm{C}$ for an hour to anneal the sample, which creates a biphasic surface layer of nickel oxide and iron oxide. After annealing, the nickel oxide/hematite samples can be used to catalyze water splitting. The use of the electrocatalyst on the substrate improved the electrolysis of water by decreasing the overpotential by approximately $300 \mathrm{mV}$. Annealing the nickel oxide and hematite decreases the overpotential by the same amount as the unannealed nickel oxide layer covering the $\mathrm{Fe}_{2} \mathrm{O}_{3}$. Both unannealed and annealed samples show photoactivity, but annealing increases the photovoltage. The physical properties are tested using transmission electron microscopy (TEM), and energy dispersive x-ray spectroscopy (EDX), which shows catalyst particles were created on the surface of the hematite nanowire array.
\end{abstract}




\section{$\underline{1 . \text { Introduction }}$}

Research into renewable energy is one area of scientific research that currently has much time and energy invested into it. The world's reliance upon nonrenewable sources of energy, such as coal and oil, poses a significant problem for future generations. Several problems created by the use of such resources are the increase in $\mathrm{CO}_{2}$ emissions, accelerating climate change, and the fact that these resources have a finite supply. Fossil fuels are the most widely used source to power the world. In 2001, fossil fuels contributed to $86 \%$ of worldwide energy used [1]. In the United States, in $2013,67 \%$ of electricity was still being produced by fossil fuels, and merely $6 \%$ originated from renewable sources [2].

Other sources of energy such as wind and solar energy have been increasing in popularity. In solar energy usage, sunlight can be harvested using four methods: 1) photovoltaic cells, which convert light directly to electricity, 2) photosynthesis, which is nature's method of converting light to fuels, 3) semiconductor/liquid junctions, which combine the previous two by converting light to electricity which can be used to create fuels, or 4) solar thermal, which stores solar energy in the form of heat [3]. Photovoltaic cells are the most popular form of industrially harvesting solar power in solar fields. However, in using solar energy, several issues exist and must be overcome before it can be used to power the world to the same extent as fossil fuels do. A complication is that the amount of sunlight a given region of the world receives has diurnal and seasonal variation making the amount of energy that can be harvested on a given day inconsistent. Therefore, it is necessary to store solar energy to be accessed during periods of low sunlight when direct conversion of energy from light to electricity is not possible.

Several methods currently exist for storing solar energy. One method is to store the energy with the use of batteries. Using batteries is expensive when the cost of storage is compared to the 
energy density, approximately $0.5 \mathrm{MJ} \mathrm{kg}^{-1}$, that can be stored. Another method is to store light energy in the form of chemical fuels, in the chemical bonds of hydrogen gas, which has an energy density of approximately $140 \mathrm{MJ} \mathrm{kg}^{-1}$. The energy density stored in chemical bonds of hydrogen is much greater than that of batteries [4]. The stored energy in hydrogen can then be released in several ways to produce usable electric power. Hydrogen can be combusted with no $\mathrm{CO}_{2}$ byproduct. Hydrogen and oxygen can also be used in fuel cells, which produce electricity when the $\mathrm{H}_{2}$ and $\mathrm{O}_{2}$ gases recombine to form water [5].

Currently, the majority of hydrogen gas is created from crude oil processing [6]. If a scalable method for utilizing water to create hydrogen gas can be found, it would decrease reliance on fossil fuels, due to the abundance of water on Earth. Semiconductor/liquid junctions can be used for creating $\mathrm{H}_{2}$ and $\mathrm{O}_{2}$ from water. Semiconductors can absorb sunlight at various wavelengths which excites the electrons to the conduction band and creates holes in the valence band. The electrons and holes in the semiconductor drive electrochemical reactions such as water splitting if they have the requisite amount of energy. When the water is split, $\mathrm{H}_{2}$ can be collected and stored. $\mathrm{O}_{2}$ is also created in this process, but is usually not stored as fuel.

There are many semiconductors that can be used to drive the electrolysis of water. One of the more studied ones is titanium oxide, but it is inefficient due to a large band gap and poor charge-carrier transport properties. Therefore, other materials must be found. In order to split water, semiconductors must have an appropriate band gap, the amount of energy that must be absorbed to excite electrons in the valence band to move to the conduction band. $1.23 \mathrm{eV}$ is minimum required thermodynamic energy to electrolyze $\mathrm{H}_{2} \mathrm{O}$ to $\mathrm{O}_{2}$ and $\mathrm{H}_{2}$. However, an appropriate single-material semiconductor band gap for photoelectrolysis is $1.6 \mathrm{eV}-2.4 \mathrm{eV}$ to account for the required kinetic activation energy barrier that is necessary for practical current 
densities [7]. One semiconductor that has an appropriate band gap of $2.2 \mathrm{eV}$ is $\alpha-\mathrm{Fe}_{2} \mathrm{O}_{3}$, or hematite [8]. While water can be split using hematite as the semiconducting electrode, a catalyst is necessary to aid in driving the reaction by decreasing the overpotential, the excess potential necessary to begin the reaction. Nickel oxide ( $\mathrm{NiOx})$ is one catalyst that can be used. Nickel iron oxide ( $\mathrm{NiFeOx}$ ) has been proven to be an effective catalyst; therefore, the combination of nickel oxide as a catalyst on iron oxide, hematite, was of interest to be investigated [9].

A new method of catalyst application using oxygen plasma has been explored. First a solution of the desired metal ions was created then applied to the substrate. The technique was first tested using fluorinated tin oxide (FTO) on glass to test the viability of the method. FTO was used as the substrate and various nickel and iron solutions to create the catalyst coating. The solutions were placed on the FTO substrate and then exposed to oxygen plasma. After electrochemical testing, the added catalyst had been shown to successfully decrease the overpotential of oxygen evolution from water. Once the new method had been proven successful for applying the catalyst, the method was used to apply $\mathrm{NiOx}$ to $\alpha-\mathrm{Fe}_{2} \mathrm{O}_{3}$ nanowires.

There are several methods that have been reported in the literature about preparation of nickel iron oxide catalysts. Electrodeposition of the nickel iron catalyst from a solution of nickel sulfate and iron sulfate in ultrapure water is one such method. After the application of the nickel iron oxide catalyst, there was a significant decrease in the overpotential when applied to a gold substrate [10]. Electrodeposition has the benefit of a fairly regular distribution of the catalyst across the entire surface, but it can take a long period of time to apply the catalyst depending on the amount of addition desired. Another method that has been utilized is spin-coating with a subsequent annealing step. This, too, has shown that the application of nickel iron oxide or other nickel derived catalysts lowers the overpotential of water electrolysis [11]. Spin coating is a fairly 
quick way to apply a catalyst; however, it is inexact in the amount applied, and it only works best when applying a thin layer. Additionally, for the catalyst to be fully integrated into the substrate an annealing step, which takes time, must follow the original spin coating.

The new method being tested, using plasma oxidation, has not been attempted before, and is of interest because it is a quick and simple process to apply catalysts to substrates. It can apply larger amounts of catalyst in shorter amounts of time than electrodeposition. The plasma oxidation step both oxidizes the catalyst and integrates it into the substrate. The exposure times are short, less than one minute for the application during which the catalyst is fully formed during the plasma exposure. 


\section{$\underline{\text { 2. Background }}$}

Semiconductors with appropriate band gaps can absorb sunlight and drive oxidation and reduction reactions. Semiconductors have a valence band, where their ground state electrons are located, and a conduction band, where the excited electrons are located. The minimum amount of energy necessary to excite an electron from the valence band to the conduction band is called the band gap. Certain semiconductors, such as hematite, can absorb wavelengths of visible light to excite the electrons to the conduction band. Once the electrons have been moved to the conduction band, electrolysis of water can occur if the right amount of energy to begin the reaction is at the semiconductor/electrolyte junction.

The reaction that splits $\mathrm{H}_{2} \mathrm{O}$ into $\mathrm{O}_{2}$ and $\mathrm{H}_{2}$ is actually two half reactions that occur at different semiconductor/liquid interfaces within the circuit. The anode will drive the oxygen evolution reaction (OER), while the cathode will drive the hydrogen evolution reaction (HER). Semiconductors can be doped with either n-type or p-type catalysts. N-type semiconductors are doped with electron donors, and are, therefore, electron rich. P-type semiconductors are doped with electron acceptors, and are, therefore, electron deficient [3]. Hematite and nickel oxide are both n-type materials that are used in the circuit's anode that drive the half reaction that produces oxygen from water. For a chemical reaction to occur, enough energy to begin the reaction must be supplied to the system. More potential than that needed to electrolyze water, $1.23 \mathrm{~V}$, is needed due to the kinetic activation loss in energy. Different semiconducting materials can offset this overpotential if they can absorb light energy and align with the electrolyte in order to drive the reaction. Lowering the overpotential increases the efficiency of the reaction by wasting less energy in order to create $\mathrm{O}_{2}[3]$. 
Water can be split by hematite in alkaline conditions when the hematite is most stable. When hematite is in pure water or acidic conditions, it is susceptible to corrosion and no longer able to catalyze OER. The addition of the catalyst can decrease the overpotential necessary in order to catalyze the reaction. It was predicted that the addition of $\mathrm{NiFeOx}$ to the fluorinated tin oxide (FTO) substrates and the addition of NiOx to the hematite nanowires would decrease the overpotential necessary to electrolyze water. The addition of catalysts on both substrates was proven to improve the electrolysis of water by decreasing the overpotential. 


\section{Experimental}

\subsection{Electrocatalyst Preparation}

First, fluorinated tin oxide (FTO) on glass was used as the control substrate for the application of electrocatalysts. FTO is used because it is not susceptible to alterations under the high temperatures of a plasma flame. Also, FTO is generally used to prove the catalysts effects because it has such a large overpotential that any faradaic current generated at lower potentials during electrochemical testing is due to the catalyst applied, not the substrate itself. Nickel oxide and iron oxide catalysts were applied to the FTO substrates. To prepare the FTO electrodes were loaded with varying concentrations of $\mathrm{Ni}$ and Fe particles.

\begin{tabular}{|c|c|}
\hline $\mathrm{Ni}\left(\mathrm{NO}_{3}\right)_{2}$ & $\mathrm{Fe}\left(\mathrm{NO}_{3}\right)_{2}$ \\
\hline 1 & 0 \\
\hline 3 & 1 \\
\hline 1 & 1 \\
\hline 1 & 3 \\
\hline 0 & 1 \\
\hline
\end{tabular}

Table 1: The molar ratios of $\mathrm{Ni}\left(\mathrm{NO}_{3}\right)_{2}$ to $\mathrm{Fe}\left(\mathrm{NO}_{3}\right)_{2}$ in the tested solutions.

The solutions were made to $1 \mathrm{M}$ in deionized water in order to ensure enough catalyst was applied to the substrate [10]. Each of these solutions were placed on FTO using a syringe to ensure equal amount of solution was applied each time and exposed to oxygen plasma to oxidize the catalysts. The amount of solution applied was $0.1 \mathrm{~mL} / \mathrm{cm}^{2}$. The exposure duration was approximately $30 \mathrm{~s}$ in $10 \mathrm{~s}$ increments with $5 \mathrm{~s}$ rest periods between exposures to ensure the substrate would not crack due to overheating, enough time for all of the water to evaporate and oxidize the nickel and iron ions in solution to nickel iron oxide on the substrate, with the upstream atmospheric plasma reactor power set at $605 \pm 10 \mathrm{~W}$, which was enough power to oxidize the catalyst quickly, without overheating and damaging the sample. 
Hematite nanowire arrays were created by exposing iron sheets [8] to oxygen plasma and were used as the second substrate. FTO is a good reference to ensure the catalyst lowers the overpotential and aids in water splitting, but FTO is a conductor and, therefore, is not photochemically active. Hematite, unlike FTO, does show an increase in current when exposed to light. The hematite nanowire arrays were still attached to the iron sheets from which they were created. Solutions of $\mathrm{Ni}\left(\mathrm{NO}_{3}\right)_{2}$ were made then applied on the hematite nanowires. $0.1 \mathrm{~mL} / \mathrm{cm}^{2}$ of solution was applied. The surface area was determined through geometric measurements of the arrays. Several concentrations of $\mathrm{Ni}\left(\mathrm{NO}_{3}\right)_{2}$ solutions were tested. $1 \mathrm{M} \mathrm{Ni}\left(\mathrm{NO}_{3}\right)_{2}$ in deionized water was determined to be the optimum concentration through electrochemical testing of varying concentrations. Then, the hematite with solution was exposed to oxygen plasma for oxidation. It was exposed for $30 \mathrm{~s}$ in $10 \mathrm{~s}$ increments at a power of $605 \pm 10 \mathrm{~W}$.

Some of the hematite nanowires with nickel oxide catalyst were then placed in an oven to anneal the sample. It was hoped that an alloy of nickel iron oxide could have been created through an annealing step at a high temperature. The hematite with nickel oxide was removed from the iron sheet backing by simply lifting the hematite off using magnetic forceps. Annealing was performed on the iron sheet synthesized hematite and nickel oxide through a heat treatment of $550^{\circ} \mathrm{C}$ for one hour in an oven. The time and temperature at which to anneal the samples were determined through literature references and testing samples' stability after annealing at various temperatures for various durations. Higher temperatures were not viable due to the instability of hematite at those temperatures. The samples were heated at $10^{\circ} \mathrm{C}$ per minute and then allowed to cool in air through natural convection [12]. 


\subsection{Characterization}

The surface characteristics of the hematite/nickel oxide samples were determined by scanning electron microscopy (SEM) and transmission electron microscopy (TEM). The compositions of the samples were determined by energy dispersive spectrometry (EDX) mapping in SEM and TEM.

Electrochemical characterization for FTO and hematite electrodes were completed in $1 \mathrm{M}$ $\mathrm{KOH}$ electrolyte in $18.6 \mathrm{M} \Omega^{*} \mathrm{~cm}$. A three electrode setup was used with a counterelectrode of platinum and an Accumet $\mathrm{Ag} / \mathrm{AgCl}$ reference electrode. All electrochemical testing was performed using a Princeton Applied Research galvanostat/potentiostat Model 273A. Photoelectrochemical cell (PEC) testing using linear sweep voltammetry at a scan rate of $25 \mathrm{mV} / \mathrm{s}$ with an initial potential of $0 \mathrm{~V}$ and varying final potentials was done for each sample. All hematite electrodes were subjected to PEC testing in the dark and under direct artificial sunlight from a $1 \mathrm{Sun}\left(100 \mathrm{~mW} / \mathrm{cm}^{2}\right)$ AM1.5 Xenon lamp. As FTO is a conductor and not a semiconductor, variations in electronic behavior will not occur with exposure to sunlight. Therefore, it is not necessary to perform electrochemical testing under artificial sunlight as it is for hematite. Open circuit potential (OCP) testing was performed on the hematite samples in order to determine the difference in potential created by exposure to light. This was done by allowing the OCP program to run for $90 \mathrm{~s}$ in the absence of light; then, the sample was exposed to light for $90 \mathrm{~s}$, and the two steps were repeated. This was to determine the difference in photovoltage. 


\section{$\underline{4 . \text { Results and Discussion }}$}

\subsection{Exploration of Methodology Using an FTO Substrate}

When plasma oxidation was used with FTO, the catalysts formed an irregular film and adhered well to the substrate. Once the samples were created electrochemical testing was done, and a current-potential (IV) plot was obtained. The data obtained were then processed to change the values to current density by dividing the current by the measured geometric area of the electrode. The values of the potentials versus the reversible hydrogen electrode were found by adding the potential value to the saturated $\mathrm{Ag} / \mathrm{AgCl}$ potential, $0.197 \mathrm{~V}$, and the $0.059 \mathrm{~V} * 14$ to account for the $\mathrm{pH}$ of the electrolyte. During the electrochemical testing, small portions of the catalyst did not remain bound to the substrate.

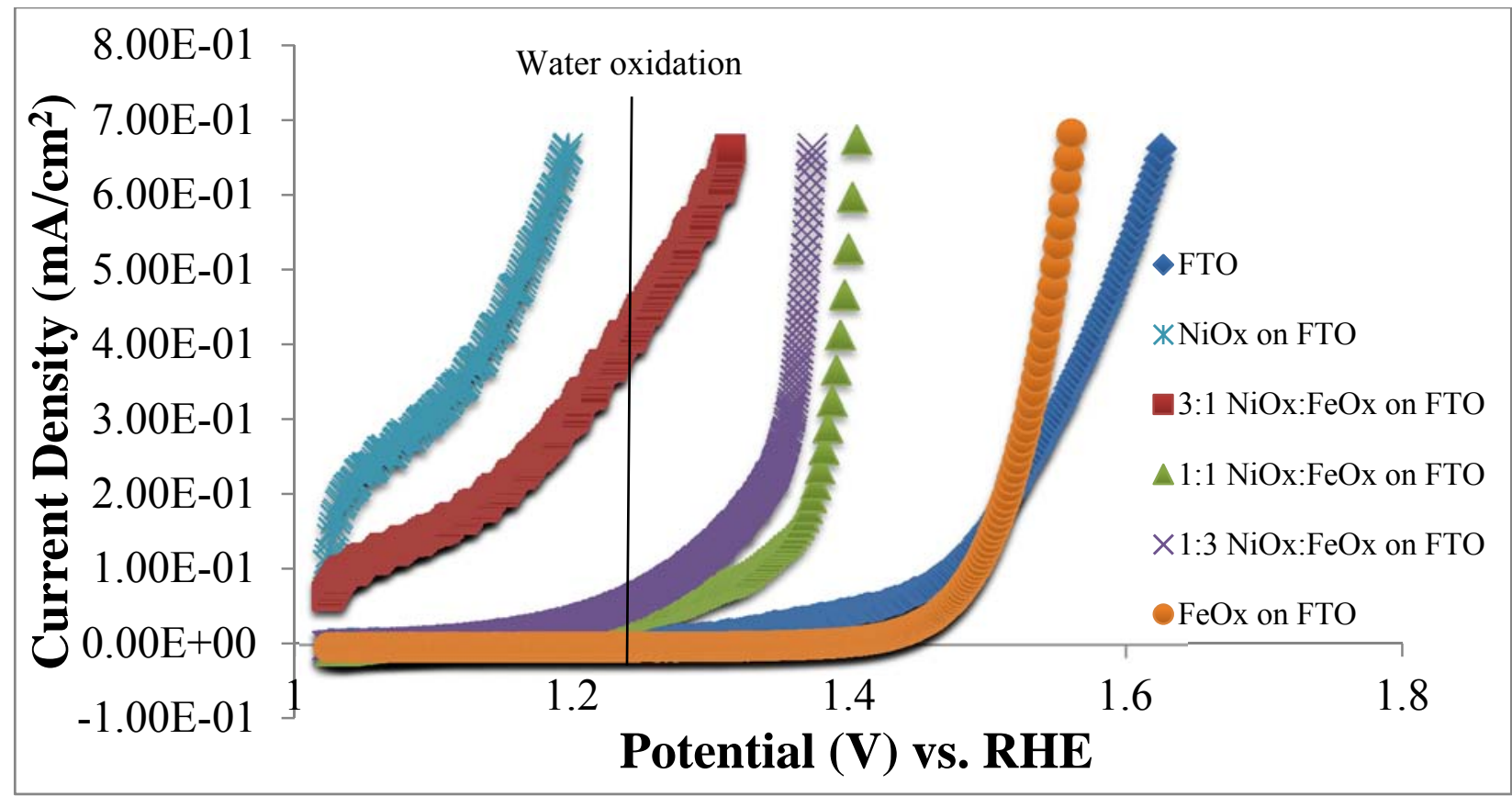

Figure1. Current density-potential curve of various nickel and iron catalysts on an FTO substrate 
FTO is used as a substrate because it has a large overpotential, and therefore the reduced overpotential can be entirely ascribed to the electrochemical effects of the added catalyst. FTO was first used in the experiment in order to prove the plasma oxidation method a viable process to apply catalysts. With a cursory observation of the FTO before and after plasma oxidation of the solutions applied to the FTO, a clear difference is observed due to the creation of a solid amorphous film on the surface of the substrate. When the FTO was tested electrochemically, the current density-potential curves of the varying ratios of nickel oxide: iron oxide on FTO show that all of the catalysts decrease the overpotential. The extent of the decrease is dependent upon the nature of the catalyst applied. The largest decrease in the onset potential is seen when using pure nickel oxide as the catalyst. As the nickel oxide concentration in the catalyst decreases, the overpotential increases, when compared to using pure nickel oxide as a catalyst. The following table shows the difference in the potential with the catalyst and without the catalyst.

\begin{tabular}{|c|c|}
\hline Catalyst & $\Delta \mathrm{V}$ \\
\hline NiOx & 0.43 \\
\hline $3: 1 \mathrm{NiOx}: F e O x$ & 0.32 \\
\hline $1: 1 \mathrm{NiOx}: F e O x$ & 0.21 \\
\hline $1: 3 \mathrm{NiOx}: \mathrm{FeOx}$ & 0.24 \\
\hline FeOx & 0.06 \\
\hline
\end{tabular}

Table 2: The potential of the catalyst coated FTO is subtracted from the potential for FTO at the current density of $6.00 \times 10^{-1} \mathrm{~mA} / \mathrm{cm}^{2}$.

\subsection{Nickel Oxide Catalyst on Hematite sans Annealing}

Before applying the nickel oxide solution, hematite had a red color. After the solution was applied and oxidized using the upstream plasma reactor, a gray film, nickel oxide, had formed on the surface of the nanowires. The physical characteristics were deduced using a variety of techniques. Viewing the nickel oxide coated nanowires in the TEM, it is seen that the dispersion is not a complete layer of nickel oxide across the entire nanowire surface. There are some regions that 
contain a nickel oxide layer, while other regions have a scattering of particles, creating an amorphous film, like it did on FTO.
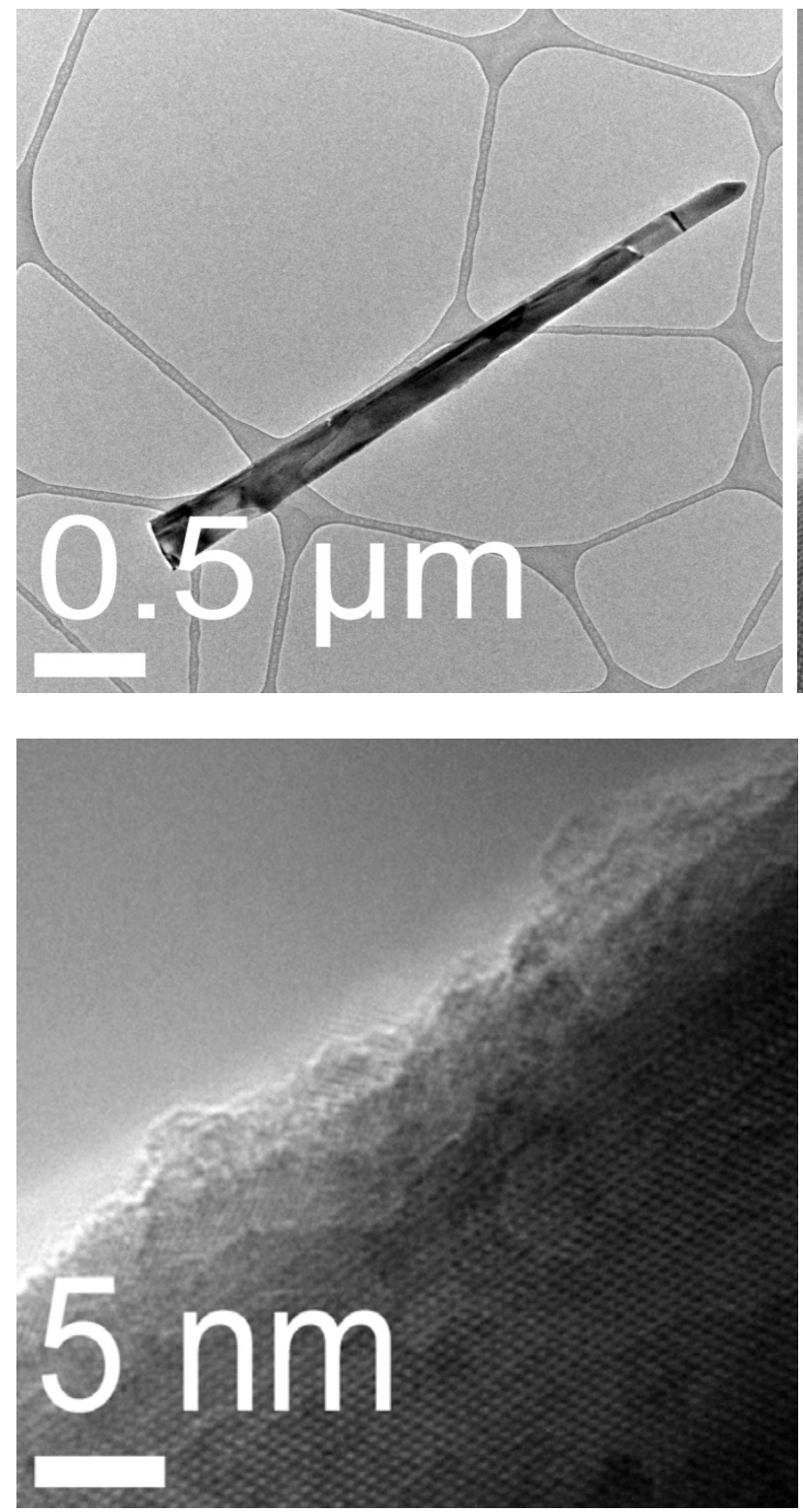

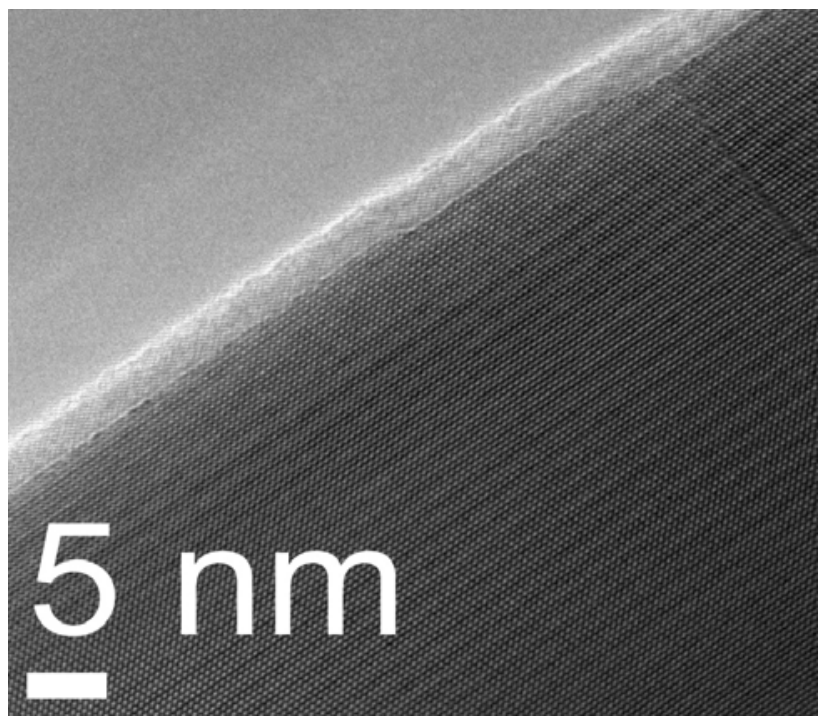

Figure 2:

Top Left: Top view of a complete unannealed nickel oxide coated nanowire

Top Right: Side view of the unannealed nanowire with a fine nickel oxide layer (light gray) on hematite (dark gray)

Bottom Left: Side view of the unannealed nanowire with nickel oxide particles scattered in irregular layers on the nanowire surface 

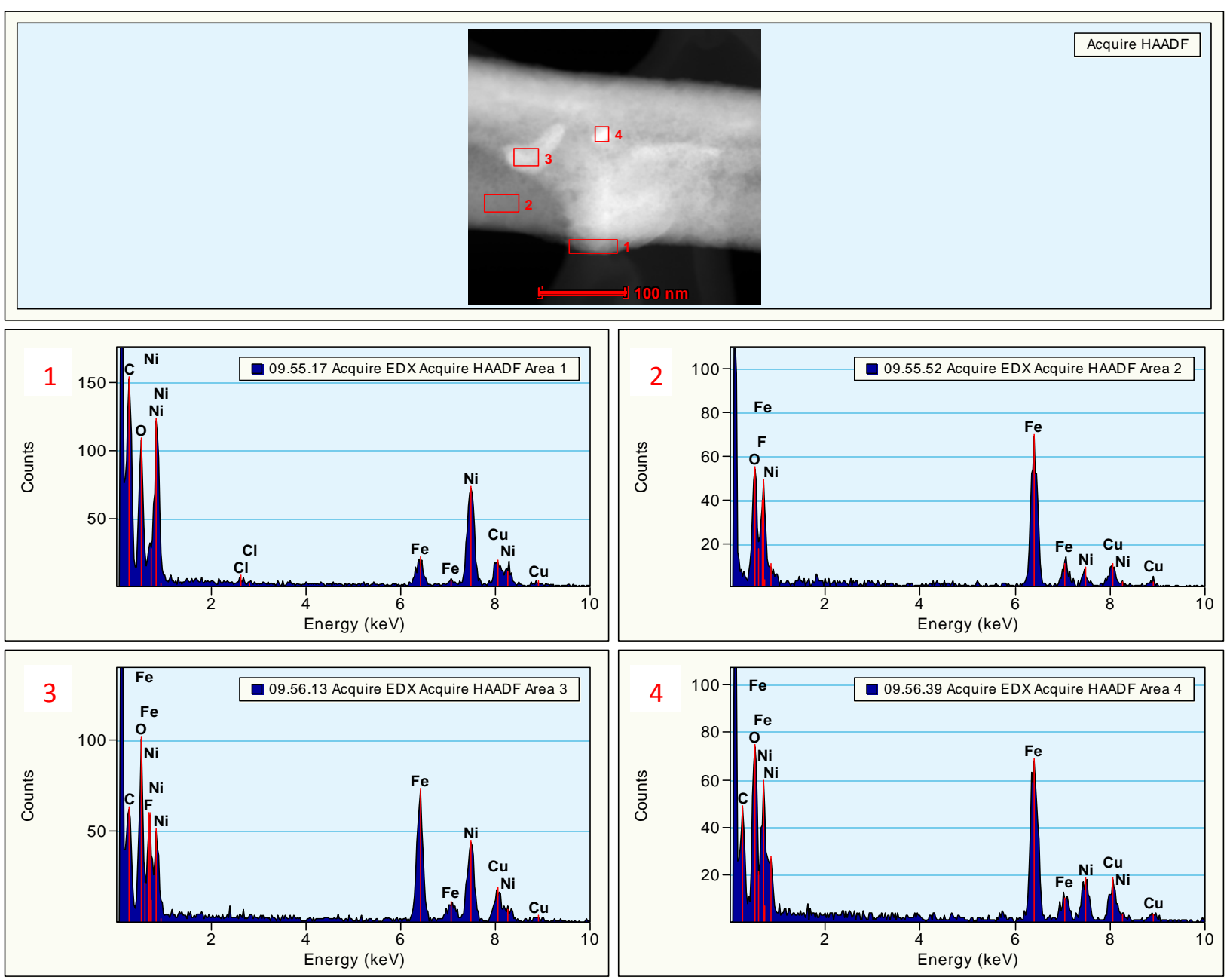

Figure 3: TEM-EDS analysis of the elemental composition of the nickel oxide coated hematite nanowires

Figure 2 shows the surface view of the nanowires. The application of the nickel oxide resulted in an uneven distribution of the catalyst. There are regions with a fine layer of nickel oxide, while other regions have particles of nickel oxide. Figure 3 shows an elemental analysis of the surface of a hematite nanowire. In region 1, nickel and oxygen are the most prominent elements, with very little iron. This indicates that this region is almost entirely the coating of catalyst, likely nickel oxide. In region 2, a large particle is not observed on the surface; however nickel, iron, and oxygen are all present. Nickel is not as predominant as in region 1. Iron and oxygen are expected because the substrate is $\mathrm{Fe}_{2} \mathrm{O}_{3}$. In regions 3 and 4, smaller particles can be 
seen on the nanowire surface. The EDX indicates the presence of nickel, iron and oxygen, which indicates the presence of both the desired catalyst and the substrate. The nickel oxide exists as a separate phase on the surface of the iron oxide.

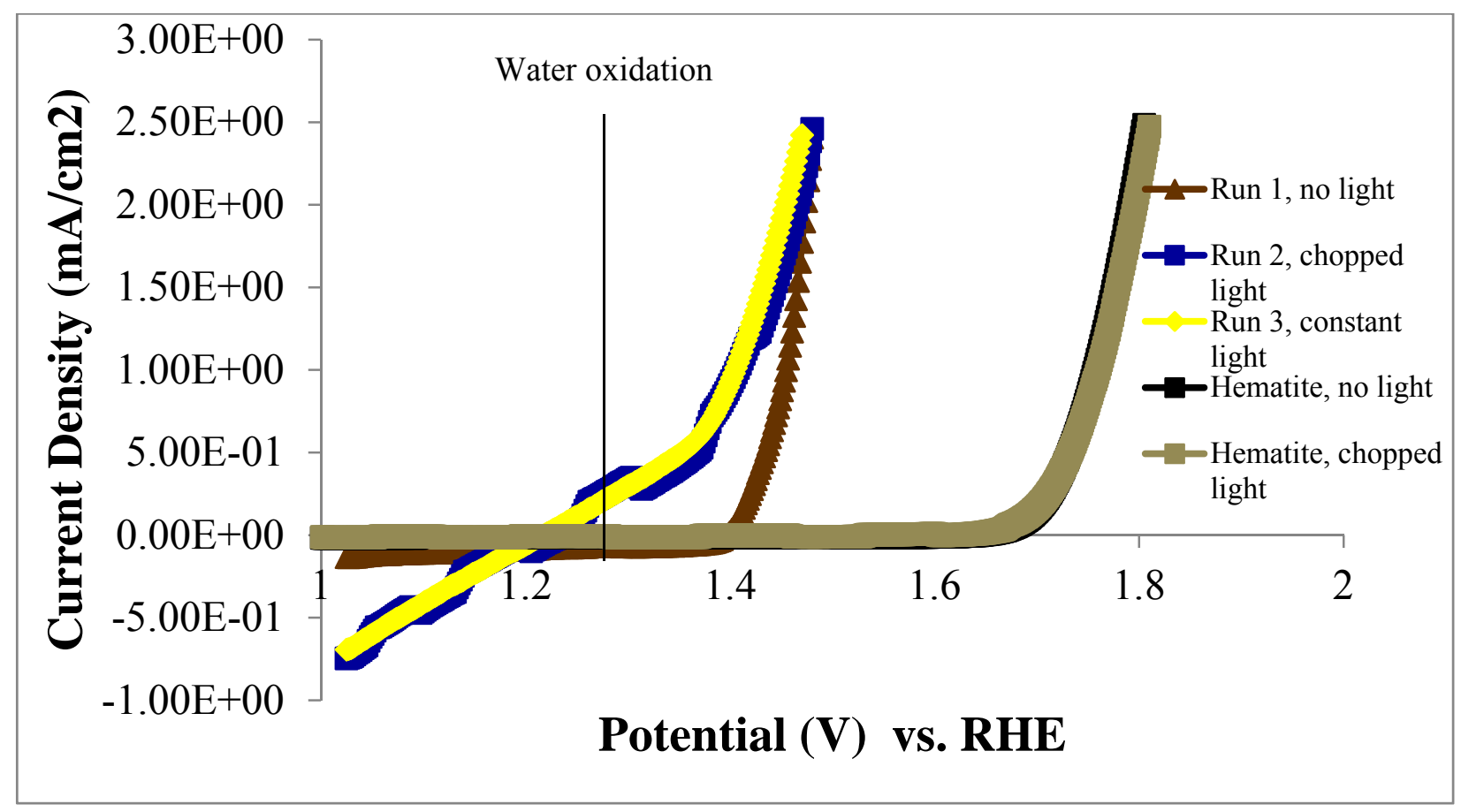

Figure 4: Current density vs. potential curve from photoelectrochemical testing of the $\mathrm{NiOx}$ coated hematite in reference to hematite.

Figure 4 shows the difference in the potential at which the water oxidation occurs with hematite alone compared to the potential with nickel oxide coating the hematite nanowires. There is over $0.3 \mathrm{~V}$ decrease in the onset when the nickel oxide is used as a catalyst. The sweeps with illumination decreases the onset potential more than in the dark. The decrease in potential shows that the nickel oxide is an effective catalyst when applied to hematite. Also, the photocurrent is slightly higher with the catalyst on the surface, as the chopped light run of the nickel oxide coated sample has a difference in the photocurrent of approximately $40 \mu \mathrm{A} / \mathrm{cm}^{2}$, whereas hematite has a smaller photocurrent, approximately $8 \mu \mathrm{A} / \mathrm{cm}^{2}$. 


\subsection{Nickel Oxide Catalyst on Hematite with Annealing}

The hematite with nickel oxide catalyst was removed from the iron backing before being placed in the oven to anneal. After annealing in the oven at $550^{\circ} \mathrm{C}$ for one hour, the catalyst coated hematite appeared to gray. There was no observable difference in appearance between the annealed and unannealed $\mathrm{NiOx} /$ hematite samples. The annealed samples were characterized in a similar manner to those that remained unannealed. The physical characteristics were primarily characterized by TEM.
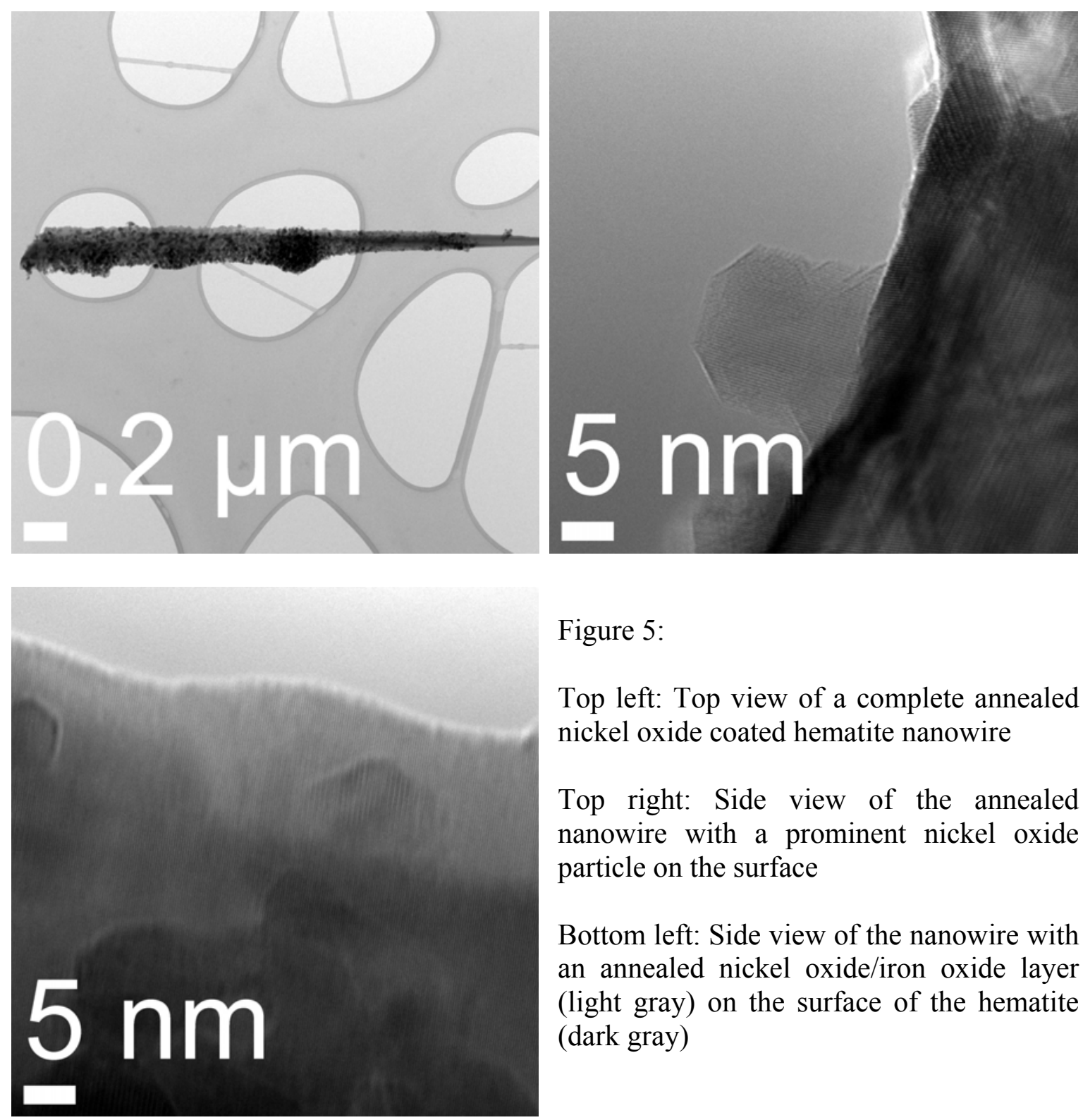

Figure 5:

Top left: Top view of a complete annealed nickel oxide coated hematite nanowire

Top right: Side view of the annealed nanowire with a prominent nickel oxide particle on the surface

Bottom left: Side view of the nanowire with an annealed nickel oxide/iron oxide layer (light gray) on the surface of the hematite (dark gray) 
After the annealing process, the nickel oxide coated hematite nanowires remain intact. The superficial appearance on the annealed nickel oxide/hematite nanowires is similar to that of the unannealed nickel oxide coated nanowires. There are regions with layers of the catalyst and other regions with particles creating an amorphous surface. The main difference is seen when viewing the elemental composition analysis through the use of EDX.
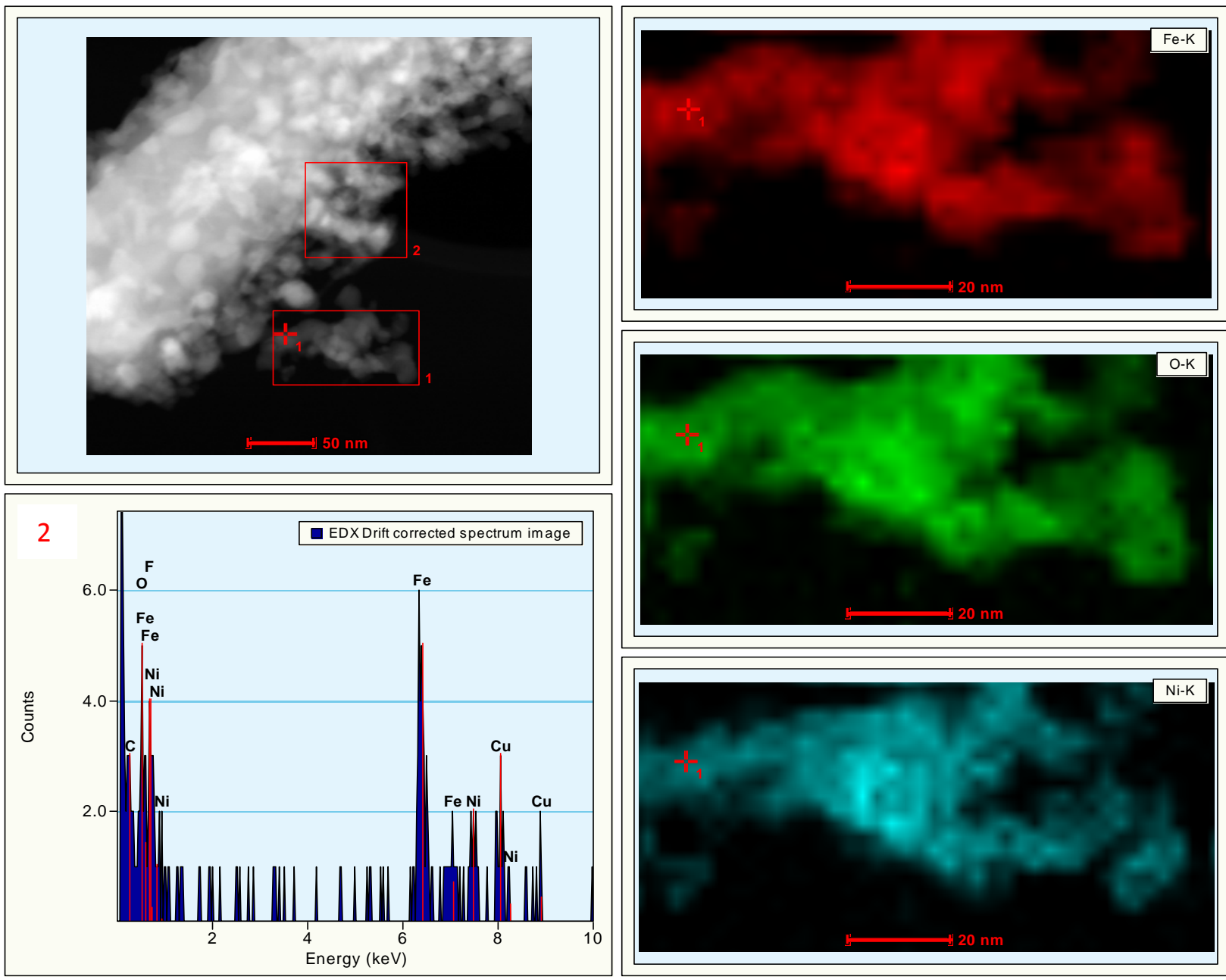

Figure 6: TEM-EDX analysis for elemental composition and dispersion of the annealed nickel oxide coated hematite nanowires

Region 1 shown in Figure 6 is a particle on the surface of the nanowire. The elemental dispersion pattern in this region shows that nickel, iron, and oxygen are located throughout the particle. This is different from the samples that remained unannealed because the large particles, 
approximately $10-20 \mathrm{~nm}$ in diameter, on the surface of the nanowire were mainly composed of nickel and oxygen, nickel oxide. There was very little iron. In the annealed samples, iron oxide had been diffused through the surface particles due to the additional annealing step. In region 2, which is another particle on the surface, there is a large iron oxide concentration, not only nickel oxide. It is clear through EDX analysis that unlike the unannealed samples of hematite, which only have nickel oxide on top of the iron oxide, the iron oxide is diffused through the surface nickel oxide catalyst.

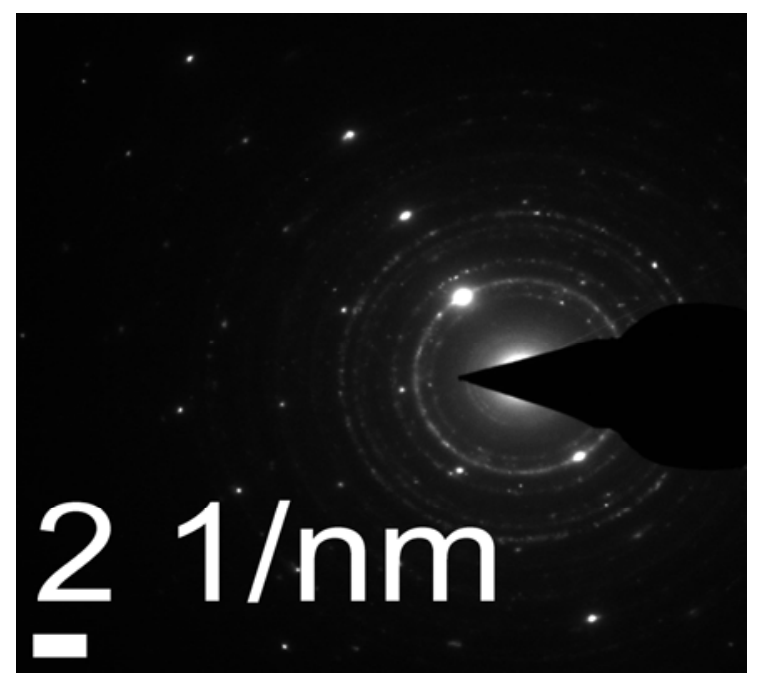

Figure 7: The selected area diffraction pattern of the annealed nickel oxide/hematite sample

Figure 7 shows the x-ray diffraction pattern. The "rings" are the diffraction pattern of nickel oxide. The "stars" are the diffraction pattern of $\mathrm{Fe}_{2} \mathrm{O}_{3}$. The annealing step was undertaken in an attempt to form a nickel iron oxide alloy in the form of nanowires. The elemental diffusion pattern and the diffraction pattern disprove that an alloy was created through the additional step. Iron oxide was diffused through the surface particles and layers of nickel oxide; however, an alloy was not formed. Instead, the surface remained biphasic, containing both iron oxide and nickel oxide. 


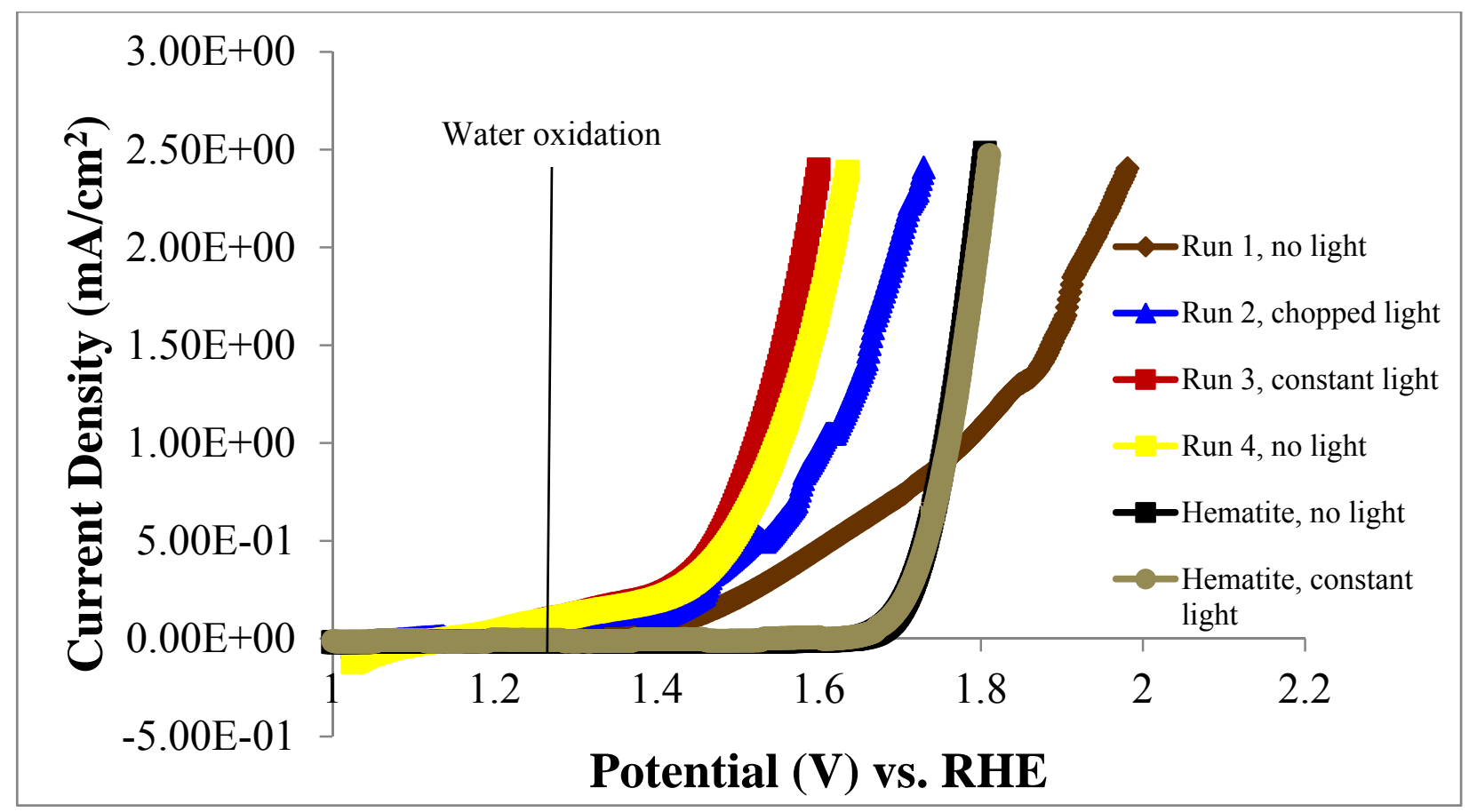

Figure 8: Current density vs. potential curve from photoelectrochemical testing of the annealed $\mathrm{NiOx}$ coated hematite in reference to hematite.

After physical characterization, the sample was characterized electrochemically. Figure 8 shows the difference in the potential at which the water oxidation occurs when using hematite alone compared to the potential with annealed nickel oxide coated hematite nanowires. There is over $0.3 \mathrm{~V}$ decrease in the onset when the nickel oxide is used as a catalyst. The unannealed samples were decreased by a similar amount. It was hoped that the annealing process would create a nickel iron oxide alloy. However, this shows that with annealing, the biphasic surface catalyst still decreases the overpotential necessary to catalyze the OER. Like the unannealed sample, there was an increase in the photocurrent with the catalyst compared to without the catalyst. This increase is very similar to the difference in the photocurrent of the unannealed sample. The difference is approximately $40 \mu \mathrm{A} / \mathrm{cm}^{2}$. 


\subsection{Comparing Annealed and Unannealed Nickel Oxide Coated Hematite}

Electrochemical tests were done on both the annealed and unannealed cases, and then compared to hematite. Open circuit potential (OCP) was performed to test the photovoltage. When light was shown onto the samples both with and without the catalyst, the potential decreased, indicating an n-type semiconductor. The extent to which the voltage decreased changed between samples. In addition to OCP, the current density-potential curves of each were compared.

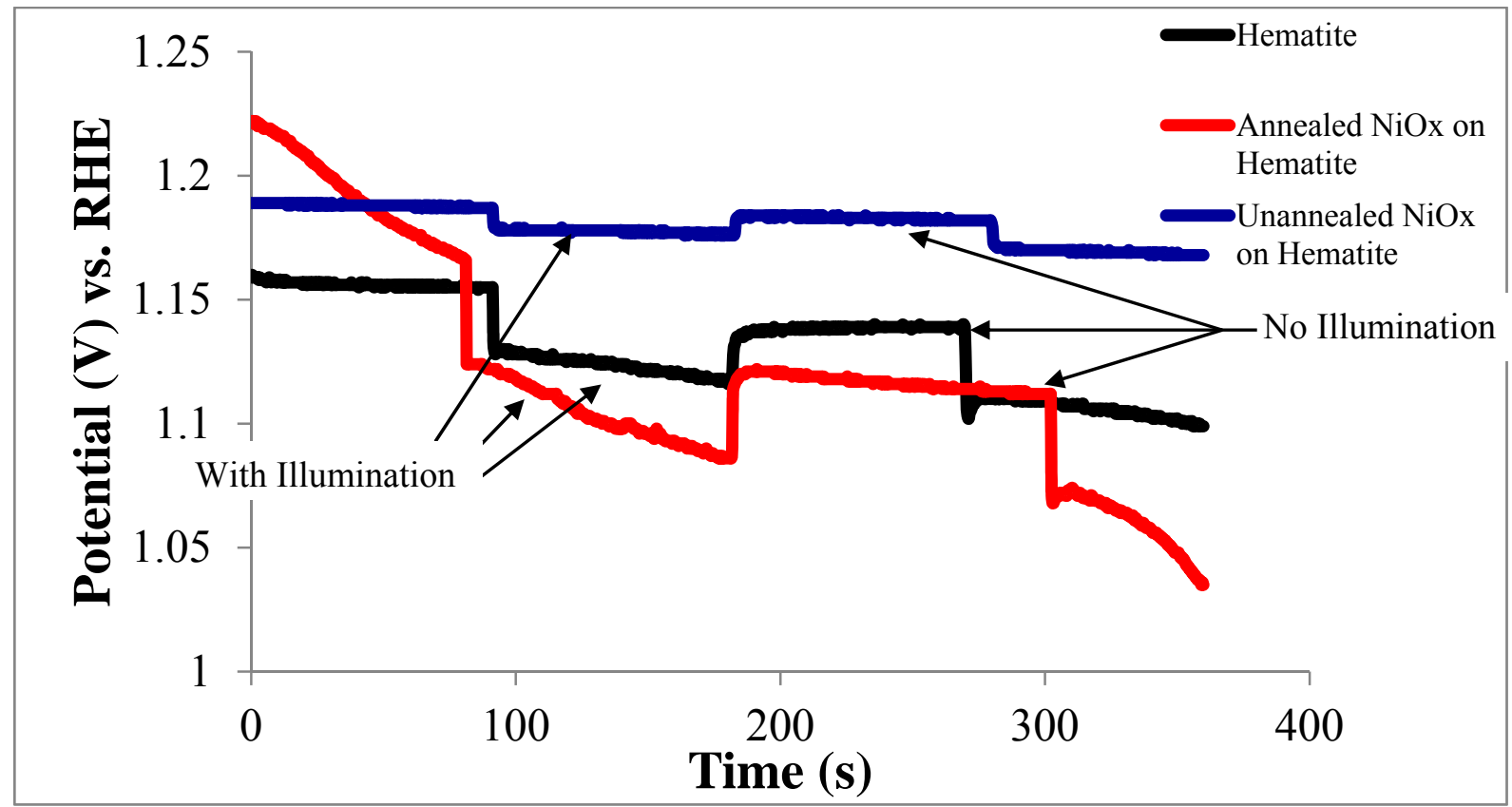

Figure 9: Open Circuit Potential graph comparing unannealed and annealed nickel oxide on hematite semiconductors with hematite alone as reference.

When viewing the OCP graph, the photopotential of each sample appears different. The hematite has approximately $31 \mathrm{mV}$ difference in potential when illuminated. The annealed nickel oxide/hematite combination has a difference of $41 \mathrm{mV}$. The unannealed nickel oxide/hematite combination shows a difference of only $11 \mathrm{mV}$. Several samples for each condition were tested using open circuit potential. Based on the data in Figure 9, the nickel oxide, when left unannealed 
on top of the hematite, decreases the photovoltage, while the annealed catalyst increases the photovoltage slightly.

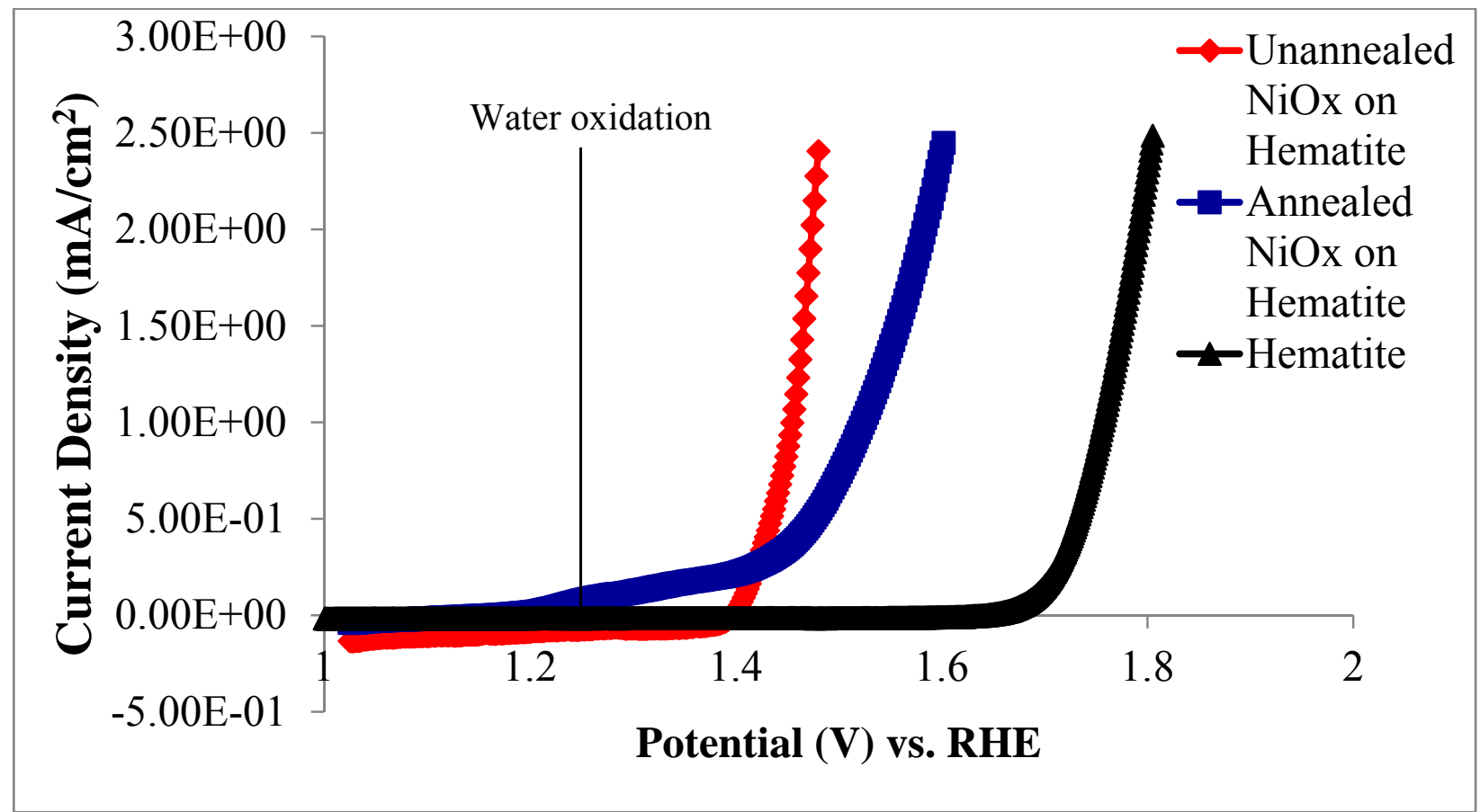

Figure 10: Current density vs. potential curve comparing unannealed and annealed nickel oxide on hematite with hematite alone as reference with no illumination during the scans.

Figure 10 demonstrates the comparison between the annealed and unannealed nickel oxide coated hematite nanowires. The difference seen is not very distinct. The annealed samples show an earlier onset of increasing current density, but the early increase is not as rapid as the onset of the unannealed samples. The unannealed samples have a more rapid increase to higher current densities. However, both the annealed and unannealed samples decreased the overpotential by approximately the same amount, which shows that the application of the nickel oxide catalyst through plasma oxidation is a viable catalyst that can improve the performance of $\alpha-\mathrm{Fe}_{2} \mathrm{O}_{3}$.

\section{Conclusions}


In this experiment, plasma oxidation of nickel iron oxide catalysts was tested on FTO to determine the viability of the new method. The method was proven to apply the catalyst. After the application, electrochemical testing showed that the catalysts decreased the overpotential for the OER. However, the use of FTO was a reference to ensure that the new method was viable. The main point of interest was to see if a nickel oxide catalyst on hematite was a viable catalyst/semiconductor combination to catalyze OER in alkaline conditions.

TEM investigations showed that the hematite nanowire arrays were decorated with nickel oxide catalyst. Nickel oxide forms particles on top of the nanowires during plasma oxidation. Some samples were annealed to try to form an alloy of nickel iron oxide. However, in the samples that were annealed, the iron oxide diffuses outward into the nickel oxide particles instead of nickel oxide diffusing inward. This creates a hematite nanowire base with a biphasic nickel oxide and iron oxide catalyst on the surface.

During electrochemical characterization the open circuit potential (OCP) is run to discover the extent of the photopotential. The unannealed samples have a potential of $11 \mathrm{mV}$, the annealed shows a potential of $41 \mathrm{mV}$, and the hematite has a potential of $31 \mathrm{mV}$. The OCP shows that the annealing step slightly improves the photopotential of hematite, while the addition of nickel oxide without annealing decreases it. The OCP does confirm that it is an n-type semiconductor. The current-potential curves demonstrate that the nickel oxide catalyst alter the overpotential drastically. The annealed and unannealed samples show a difference of approximately $0.300 \mathrm{~V}$. Both annealed and unannealed samples show similar decrease in the overpotential of hematite.

The decrease in the overpotential shows that this combination of nickel oxide and hematite could be used to electrolyze water at a lower potential than hematite could alone. There are several issues to improve upon, however. The main issue is that the photopotential and photocurrent are 
so small that improvements have to be made before it could viably be used to split water on a larger scale. Another issue is that hematite remains electrochemically unstable in $\mathrm{pH} 7$ conditions. For future endeavors, another catalyst could be tested, or a different substrate with nickel oxide and iron oxide catalysts. 


\section{$\underline{\text { 6. References }}$}

[1] N.L.D. Nocera, Proceedings of the National Academy of Sciences, 103 (2006) 15729-15735.

[2] U.S.E.I. Administration, in: Freqeuently Asked Questions, U.S. Department of Energy, 2014.

[3] P.E.L. Ming X. Tan, Sonbinh T. Nguyen, Janet M. Kesselman, Colby E. Stanton, and Nathan S. Lewis, Progress in Inorganic Chemistry, 41 (1994) 21-143.

[4] M.W. Kanan, Y. Surendranath, D.G. Nocera, Chemical Society reviews, 38 (2009) 109-114.

[5] J. Bainerman, Middle East, May (2006) 36-38.

[6] N. Nordin, AIP Conference Proceedings 1225 (2010) 498-506.

[7] M.G.W. Walter, Emily L.; McKone, James R.; Boettcher, Shannon W.; Mi, Qixi; Santori, Elizabeth A. and Nathan S. Lewis, Chemical Reviews, 110 (2010) 6446-6473.

[8] B.D. Chernomordik, H.B. Russell, U. Cvelbar, J.B. Jasinski, V. Kumar, T. Deutsch, M.K. Sunkara, Nanotechnology, 23 (2012) 194009.

[9] C.C. McCrory, S. Jung, J.C. Peters, T.F. Jaramillo, Journal of the American Chemical Society, 135 (2013) 16977-16987.

[10] M.W. Louie, A.T. Bell, Journal of the American Chemical Society, 135 (2013) 12329-12337.

[11] L. Trotochaud, J.K. Ranney, K.N. Williams, S.W. Boettcher, Journal of the American Chemical Society, 134 (2012) 17253-17261.

[12] Y. Sun, W.D. Chemelewski, S.P. Berglund, C. Li, H. He, G. Shi, C.B. Mullins, ACS applied materials \& interfaces, 6 (2014) 5494-5499. 